
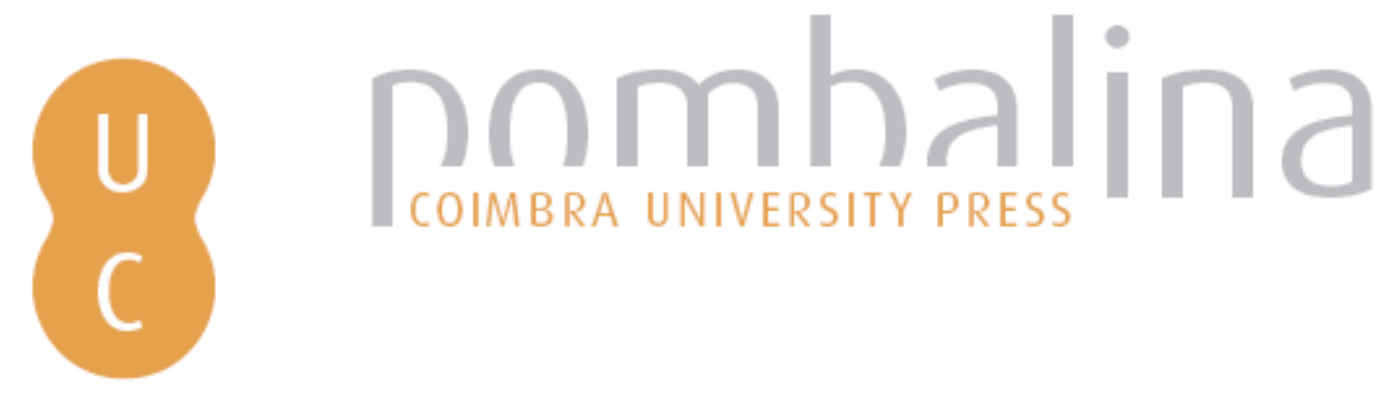

\title{
Assessment of a human body thermoregulation software to predict the thermophysiological response of firefighters
}
Autor(es):
Raimundo, António M.; Oliveira, A. Virgílio M.; Quintela, Divo A.
Publicado por: Imprensa da Universidade de Coimbra
URL
persistente:
URI:http://hdl.handle.net/10316.2/44555
DOI:
DOI:https://doi.org/10.14195/978-989-26-16-506_38
Accessed : $\quad$ 26-Apr-2023 12:34:01

A navegação consulta e descarregamento dos títulos inseridos nas Bibliotecas Digitais UC Digitalis, UC Pombalina e UC Impactum, pressupõem a aceitação plena e sem reservas dos Termos e Condições de Uso destas Bibliotecas Digitais, disponíveis em https://digitalis.uc.pt/pt-pt/termos.

Conforme exposto nos referidos Termos e Condições de Uso, o descarregamento de títulos de acesso restrito requer uma licença válida de autorização devendo o utilizador aceder ao(s) documento(s) a partir de um endereço de IP da instituição detentora da supramencionada licença.

Ao utilizador é apenas permitido o descarregamento para uso pessoal, pelo que o emprego do(s) título(s) descarregado(s) para outro fim, designadamente comercial, carece de autorização do respetivo autor ou editor da obra.

Na medida em que todas as obras da UC Digitalis se encontram protegidas pelo Código do Direito de Autor e Direitos Conexos e demais legislação aplicável, toda a cópia, parcial ou total, deste documento, nos casos em que é legalmente admitida, deverá conter ou fazer-se acompanhar por este aviso.

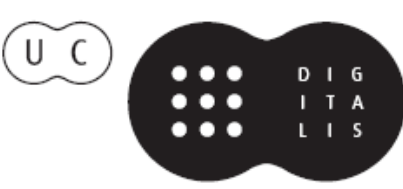




\section{ADVANCES IN}

\section{FOREST FIRE RESEARCH}

\section{8}

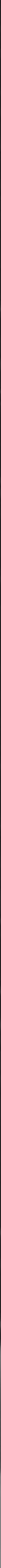




\title{
Assessment of a human body thermoregulation software to predict the thermophysiological response of firefighters
}

\author{
António M. Raimundo ${ }^{1 *}$; A. Virgílio M. Oliveira ${ }^{2}$; Divo A. Quintela ${ }^{1}$ \\ ADAI-LAETA, Department of Mechanical Engineering, Faculty of Sciences and Technology of the \\ University of Coimbra, Portugal. \{antonio.raimundo@dem.uc.pt*\} \\ ${ }^{2}$ Department of Mechanical Engineering, Coimbra Institute of Engineering of Polytechnic \\ Institute of Coimbra, Portugal, \{avfmo@mail.isec.pt\}
}

\begin{abstract}
Firefighting requires hard work in very hot environments that often lead to a continuous increase of the heat stored in the human body, promoting heat stress and heat-related illnesses. Due to safety reasons of the individuals involved, a complete characterization of the evolution of the thermal stress state of firefighters is only possible through numerical simulations of the thermophysiological behavior of the human body.

The present work has two main objectives: (i) the assessment of the effectiveness of some body cooling techniques capable to mitigate the risk of hyperthermic stress; and (ii) the evaluation, test and validation of the ability of a human body thermoregulation software to predict in detail the thermophysiological response of firefighters.

The software under evaluation, the HuTheReg program, was developed by the authors. This tool is composed by several modules, namely for the calculation of the human body thermophysiological response, the heat and water transport through clothing, the heat and mass exchange between the external surface of clothing (or skin) and the environment, the start and evolution of skin injuries (pain and burn) and the detection of specific incidents.

In the field of body cooling methodologies, the cases selected embrace 3 different classes of scenarios: (i) body cooling during both exercise and recovery phases (by use of an ice jacket, by intake of very cold water or ice slurry, by both); (ii) body cooling only during the exercise phases (by use of an ice jacket, by intake of very cold water or ice slurry, by both); and (iii) body cooling only during the recovery phases by exposure to a cold environment (passive exposure, with hands and forearms immersion in cold water, with forced air movement using fans, with the use of an ice jacket, with the intake of very cold water or ice slurry, with a combination of these cooling methodologies).

The comparison between the experimental and the predicted values shows a good prediction ability of the HuTheReg program, which is a good indication of its capability to reproduce the human body thermoregulatory responses over the range of climatic conditions investigated. Although with very different effectiveness, all body cooling techniques considered proved to be capable to mitigate the level of hyperthermic stress of firefighters engaged in characteristic activities.
\end{abstract}

Keywords: Safety firefighting; Human thermoregulation modelling; Software validation; Body cooling techniques

\section{Introduction}

Firefighting requires long periods of hard work in very hot environments which often lead to a continuous increase of the heat stored in the human body, promoting heat stress and heat-related illnesses [Raimundo and Figueiredo 2009; Barr et al. 2010].

Firefighting may lead to increases in deep body temperature to values higher than $39^{\circ} \mathrm{C}$ which may have serious consequences or be even fatal [Carter et al. 1999; Raimundo and Figueiredo 2009]. Temperatures above $39^{\circ} \mathrm{C}$ represent acute hyperthermic stress. When attained, the person physical and 
mental performance substantially decreases while the risk of developing heat-related illnesses increases [Mündel et al. 2006, Lopez et al. 2008, Raimundo and Figueiredo, 2009].

The range of possible hyperthermic disorders reported in the literature [Raimundo \& Figueiredo 2009] are muscle cramping, heat exhaustion (collapse during or after exercise), introversion (violent sweating, loss of judgment, amnesia, delusions, etc.), superficial skin damage (pain and first-degree burns), heat-stroke (fainting, cessation of sweating, central nervous system alteration, etc.) and permanent injuries (burn degree greater than first, brain damage or, in more serious cases, death).

Wearing highly thermal insulating protective clothing reduces the gain of external heat, but also blocks the release of the heat produced and restricts movements. Hence, safety firefighting requires the wearing of appropriated clothing. Even so, frequently, this is not enough. In these cases, to increase the safety of firefighters, cooling techniques capable of mitigating hyperthermia should be applied [Carter et al. 1999; Selkirk et al. 2004; Giesbrecht et al. 2007; Chou et al. 2008; Lopez et al. 2008; Barr et al. 2009 \& 2010; Hostler et al. 2010; Colburn et al. 2011; Abreu et al. 2014].

Experimental studies concerning the thermophysiological response of firefighters carrying out typical firefighting activities (both structural and wildland) already exist. In these works, the recommended protective clothing and the exposure to representative environments are considered. However, due to safety reasons of the individuals involved, these trials always terminate before firefighters reach levels of hyperthermic stress with the potential to cause heat-related illnesses. Therefore, a complete characterization of the evolution of the thermal stress state of firefighters is only possible through numerical simulations of the thermophysiological behavior of the human body.

This work has two main objectives, both related to firefighters performing firefighting activities: (i) the assessment of the effectiveness of some body cooling techniques capable to mitigate the risk of hyperthermic stress; and (ii) the evaluation, test and validation of the ability of a human body thermoregulation software to predict in detail the thermophysiological response of firefighters.

\section{The Simulation Tool}

The software under test and validation, the HuTheReg program, was implemented by the authors [Raimundo and Figueiredo, 2009; Raimundo et al. 2012]. This software is composed by several modules. However, for present purposes only the ones for the calculation of the human body thermophysiological response, the heat and water transport through clothing, the heat and mass exchange between the external surface of clothing (or skin) and the environment, the start and evolution of skin injuries (pain and burn) and the detection of specific incidents within the individual are used. Due to its interdependency, all modules run iteratively in each time step until a specific convergence criterion is reached.

The simulation of the thermophysiological response is based on the Stolwijk (1971) 25 nodes thermoregulation model, improved with knowledge found in the literature [e.g., Henriques 1947; Konz et al. 1977; Wissler 1985; Huizenga et al. 1999; Fiala et al. 1999; Tanabe et al. 2002]. This 111-node model considers the human body divided in 22 segments (face, scalp, neck, chest, abdomen, upper back, lower back, pelvis, left shoulder, right shoulder, left arm, right arm, left forearm, right forearm, left hand, right hand, left thigh, right thigh, left leg, right leg, left foot and right foot). Each body segment is composed by 5 layers (core, muscle, fat, skin and clothing), the $111^{\text {th }}$ node being the central blood compartment. The model was implemented for an average man of $1.72 \mathrm{~m}$ tall, weighing $74.43 \mathrm{~kg}$ and with $14 \%$ of body fat $\left(1.869 \mathrm{~m}^{2}\right.$ of skin). For other anthropometric data, the appropriated coefficients are proportionally changed as a function of the body weight, skin area and body fat. The loss of heat by respiration is supposed to occur across the elements of the pulmonary tract. The repartition coefficients proposed by Fiala et al. (1999) were considered. 
The determination of the outer surface temperature of the clothing (or of the skin of nude segments) involves the model of simulation of the human thermophysiological response and simultaneously the heat and mass balances of the garment both considering the flow and the storage of heat and water in the clothing layer [Raimundo et al.2012]. The global algorithm is applied to each specific human body segment, but always considering its influence and interdependence with the global thermal state of the body. Thus, for each of the 22 human body segments, individual values of clothing properties must be specified, namely of mass $\left(m_{c l}\right)$, of insulation $\left(I_{c l}\right)$, of vapor permeability efficiency $\left(i_{v p}\right)$ and of radiative reflectivity $(\rho)$. Each section is either completely clothed or nude. To consider the reduction of insulation due to body movements, the $I_{c l}$ value at each human body segment is adjusted according to the person activity using the relations proposed by Oliveira et al. (2011).

The convective heat and mass transfer phenomena are predicted using the empirical relations proposed by Quintela et al. (2004) for natural convection and by Havenith et al. (2002) for forced convection. The exchange of heat by radiation between the external surfaces of the segments of the human body and between them and the surroundings, is determined by a set of expressions established by Raimundo et al. (2004).

With the HuTheReg software a significant number of data can be obtained, both for the human body as a whole and for each of the segments, namely: (i) core, muscle, fat, skin and clothing temperatures; (ii) metabolism, heat stored and flux-rates of heat, of sweat, of water and of work; (iii) thermal comfort evaluation and indexes; (iv) detection of probable appearing of heat-related disorders within the person; (v) skin pain, burn areas and corresponding degree; and (vi) a wide range of other thermophysiological parameters.

Each run can simulate up to 20 consecutive scenarios (phases), each one representing different conditions in terms of: posture, orientation, activity, intake of food/drinks, clothing, thermal environment characteristics and impinging of thermal radiation from 6 directions (cardinal, top and bottom).

\section{Material}

The scientific literature seldom presents a complete description of experimental tests, condition that is required to accurately validate mathematical models. To overcome this difficulty, the missing information was replaced by the values suggested by Raimundo and Figueiredo (2009), namely gender (man), height $\left(h^{*}=1.72 \mathrm{~m}\right)$ and weight $\left(w^{*}=74.43 \mathrm{~kg}\right)$, the clothing specific heat $\left(c_{p}{ }^{*}=1000\right.$ $\left.\mathrm{J} /\left(\mathrm{kg} .{ }^{\circ} \mathrm{C}\right)\right)$, water vapor permeability $\left(i_{v p}{ }^{*}=1\right.$ for nude body parts, $i_{v p}{ }^{*}=0$ for the body parts dressed with impermeable clothing, $i_{v p}{ }^{*}=0.15$ for boots and shoes and $i_{v p}{ }^{*}=0.38$ for "normal" clothing) and radiative reflectivity $\left(\rho^{*}=0.10\right.$ for "normal" clothing and $\rho^{*}=0.07$ for human skin). Note that the "*" symbol indicates that this value was assumed only when it was not found in the scientific paper with the report of the experiments.

Furthermore, for situations involving human thermoregulation, the clothing is rarely characterized with the necessary detail. Therefore, for the HuTheReg program, which requires the characteristics of the clothing in each body part, it was necessary to distribute the garment characteristics over the 22 body parts and for this purpose the studies of Oliveira et al. (2008) and Raimundo \& Figueiredo (2009) were considered.

\subsection{Problem Description}

The generic protocol of the cases selected for this study is composed by the following phases: (i) preliminary thermal stabilization at neutral temperature; (ii) muscle warming; (iii) exercise in a hot environment; (iv) transition period; and (v) recovering period. In some cases, phases (iii) to (v) were repeated more than once. A normal ingestion of water is also considered. 
Due to lack of essential information only some of the cases reported in the literature are suitable for the present purposes. In terms of body cooling methodology, the cases selected can be gathered in 3 different scenarios: (i) body cooling during both exercise and recovery phases (by use of an ice jacket, by intake of very cold water or ice slurry, by both); (ii) body cooling only during the exercise phases (by use of an ice jacket, by intake of very cold water or ice slurry, by both); and (iii) body cooling only during the recovery phases by exposure to a cold environment (passive exposure, with hands and forearms immersion in cold water, with forced air movement using fans, with the use of an ice jacket, with the intake of very cold water or ice slurry, with a combination of these cooling methodologies).

\subsection{Validation}

The evaluation, test and validation of the software ability to predict the human body thermophysiological behavior is performed by comparing the program predictions with experimental results from the scientific literature. For this purpose, a wide-range of conditions was considered, which included different types of thermal environment (severe cold, cold, cool, neutral, warm, hot and very hot), of exposures (uniform, sudden change and cyclical), of exercise intensities (0.8 to 4 met) and of clothing ( 0 to 4 clo). The experimental results used for validation embrace core temperatures, average and local skin temperatures and mean body temperature as well as metabolic heat production and loss.

The comparison between the experimental and the predicted values was done using the statistical parameters mean relative difference $(\delta)$ and respective standard deviation $(\sigma)$, mean square deviation $(M S D)$ and Pearson coefficient $(r)$.

\section{Results and Discussion}

Several tests were conducted but, for the present purpose and due to the lack of space, only some of them are presented.

\subsection{Exposure to a uniform environment of semi-nude individuals}

The comparisons between measured values for rectal, tympanic and skin average temperatures and predicted data for rectal, hypothalamus and skin average temperatures are shown in Figure 1. The measured and predicted values of metabolic heat production are also presented. The experimental data represent averages for semi-nude, seated individuals after 1 hour exposure to a range of environment temperatures between 5 and $50^{\circ} \mathrm{C}$, obtained for 44 persons by Wyndham et al. (1964) and for 86 individuals by Werner and Reents (1980). Comparing the predicted values with the measured ones, a good prediction ability of the program is revealed, which is a good indication of its capability to reproduce the body thermoregulatory responses of semi-nude humans over the range of climatic conditions investigated. 


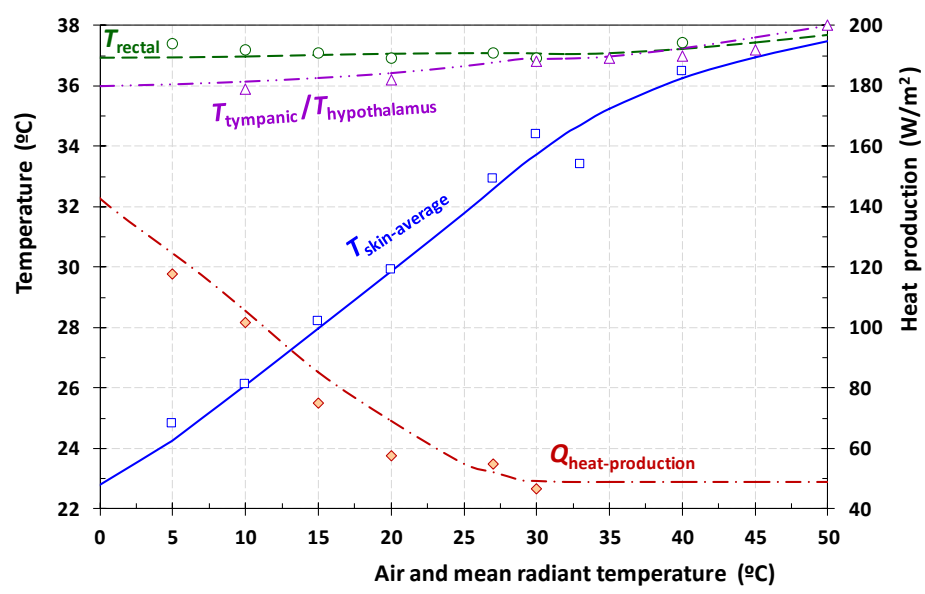

\begin{tabular}{|ccccc|}
\hline Value & $\delta$ & $\sigma$ & $M S D$ & Pearson $(r)$ \\
\hline$T_{\text {re }}(\stackrel{\circ}{\circ})$ & 0.106 & 0.226 & 0.089 & 0.740 \\
\hline$T_{\text {hyp }}(\stackrel{\circ}{\circ})$ & -0.189 & 0.137 & 0.086 & 0.980 \\
\hline$T_{\text {sk }}(\stackrel{\circ}{ } \mathrm{C})$ & 0.088 & 0.606 & 0.203 & 0.990 \\
\hline$Q_{\text {heat-prod }}\left(\mathrm{W} / \mathrm{m}^{2}\right)$ & -5.397 & 5.307 & 2.961 & 0.985 \\
\hline
\end{tabular}

Figure 1 - Comparison of measured (points) and predicted (lines) values for rectal, tympanic (exp.) / hypothalamus (calc.) and skin average temperatures and metabolism heat production, for 1 hour exposure with $T_{\text {air }}=T_{m r}, v_{\text {air }}=0.2 \mathrm{~m} / \mathrm{s}, \mathrm{RH}_{\text {air }}=50 \%$, $I_{c l}=0.1$ clo and $M=0.8$ met.

\subsection{Exposure to a passive cold environment during recovery}

To check the capabilities of the program for simulation of sudden alterations of environmental conditions, a large range of comparisons were made for abrupt changes from hot to cold and from cold to hot. As an example, in Figure 2 a comparison is shown between some of the measured and predicted values representative of the human thermo-physiological response to a rapid change from a hot environment to a cold environment and back again. The experimental data were obtained from Hardy and Stolwijk (1966), representing average values of rectal and skin average temperatures, metabolic heat production and evaporation heat loss for three men exposed to four phases: initial thermo-neutral equilibrium, 1 hour in a hot environment $\left(T_{\mathrm{air}}=T_{\mathrm{mr}}=43^{\circ} \mathrm{C}\right), 2$ hours in a cold environment $\left(17^{\circ} \mathrm{C}\right)$ and 1 hour again in hot $\left(43^{\circ} \mathrm{C}\right)$. The reasonably good agreement achieved indicates an interesting capacity of the program to predict the thermo-physiological reaction of human body in highly dynamic conditions.

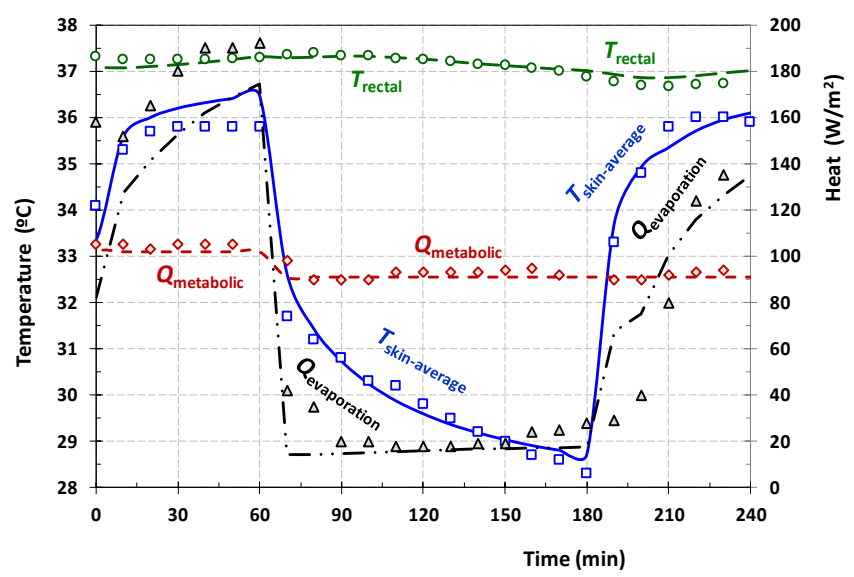

\begin{tabular}{|ccccc|}
\hline Value & $\delta$ & $\sigma$ & $M S D$ & Pearson $(r)$ \\
\hline$T_{\text {re }}(\stackrel{\circ}{ } \mathrm{C})$ & -0.005 & 0.120 & 0.024 & 0.905 \\
\hline$T_{\text {sk }}(\stackrel{\circ}{ } \mathrm{C})$ & -0.125 & 0.381 & 0.079 & 0.993 \\
\hline$Q_{\text {metab }}\left(\mathrm{W} / \mathrm{m}^{2}\right)$ & 1.912 & 2.012 & 0.585 & 0.945 \\
\hline$Q_{\text {evap }}\left(\mathrm{W} / \mathrm{m}^{2}\right)$ & 42.438 & 40.319 & 11.830 & 0.950 \\
\hline
\end{tabular}

Figure 2 - Measured (points) and predicted (lines) values of rectal and skin average temperatures and evaporation heat loss, for sudden ambient temperature changes from a hot environment of $43^{\circ} \mathrm{C}$ to a cold environment of $17^{\circ} \mathrm{C}$ and back again, with $T_{\text {air }}=T_{m r}, v_{\text {air }}=0.2 \mathrm{~m} / \mathrm{s}, \mathrm{RH}_{\text {air }}=30 \%$, $I_{c l}=0.1$ clo and $M=1.0$ met.

\subsection{Use of an ice jacket during exercise and recovery}

In the laboratory study of Chou el al. (2008), the effectiveness of the body cooling technique of wearing an ice jacket both during the exercise and the recovery phases was analyzed. For this purpose, 8 individuals (all males, $h^{(\mathrm{a})}=1.68 \mathrm{~m}, w^{(\mathrm{a})}=62.5 \mathrm{~kg},{ }^{(\mathrm{a})}$ mean values) were dressed in a firefighting personal protective ensemble. These individuals were submitted to the following protocol: (i) preliminary thermal stabilization; (ii) muscle warming ( $t=10 \mathrm{~min}, T_{a i r}=T_{m r t}=25^{\circ} \mathrm{C}, R H_{a i r}=50 \%, v_{a i r}{ }^{*}=0.2 \mathrm{~m} / \mathrm{s}, M^{*}=1.2 \mathrm{met}, I_{c l}{ }^{*}=2.54 \mathrm{clo}, i_{v p}{ }^{*}=0.28$ and $\left.\rho^{*}=0.10\right)$; (iii) transition $\left(t=10 \mathrm{~min}\right.$, the rest equal except $\left.T_{\text {air }}=T_{m r t}=28^{\circ} \mathrm{C}\right)$; (iv) exercise $(t=30 \mathrm{~min}$, 
$T_{\text {air }}=T_{m r t}=30^{\circ} \mathrm{C}, R H_{\text {air }}=50 \%, v_{\text {air }}{ }^{*}=0.2 \mathrm{~m} / \mathrm{s}, M^{*}=3.0$ met, $I_{c l}{ }^{*}=2.54 \mathrm{clo}, i_{v p}{ }^{*}=0.28$ and $\left.\rho^{*}=0.10\right)$; and (v) recovery $\left(t=10 \mathrm{~min}, T_{\text {air }}=T_{m r t}=30^{\circ} \mathrm{C}, R H_{\text {air }}=50 \%, v_{\text {air }}{ }^{*}=0.2 \mathrm{~m} / \mathrm{s}, M^{*}=0.8 \mathrm{met}, I_{c l}{ }^{*}=2.18 \mathrm{clo}, i_{v p}{ }^{*}=0.37\right.$ and $\left.\rho^{*}=0.11\right)$. Figure 3 shows the experimental results obtained by Chou et al. (2008) for the rectal $\left(T_{r e}\right)$ and mean skin $\left(T_{s k}\right)$ temperatures as well as the predicted values. A very good agreement was achieved for both temperatures, particularly for the rectal temperature.

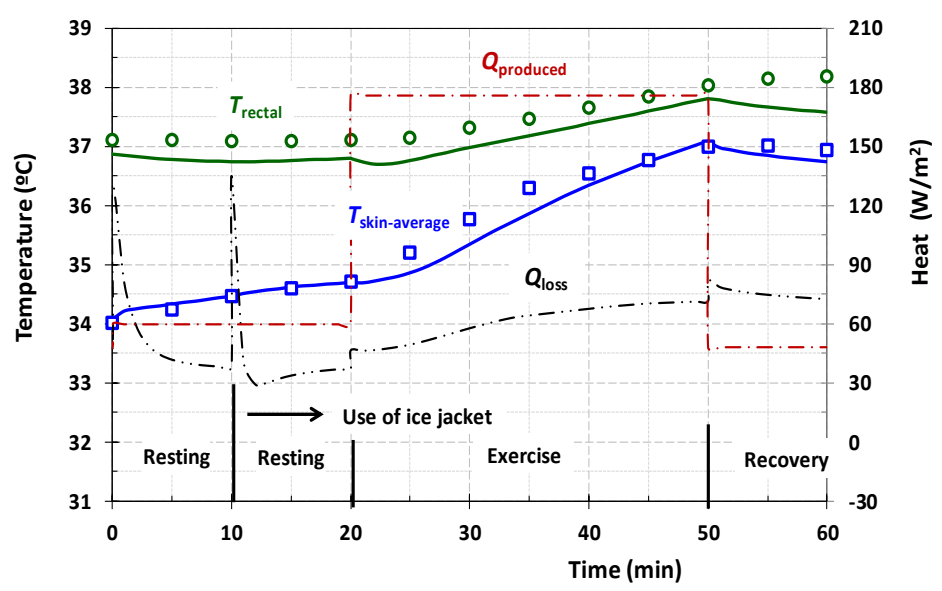

\begin{tabular}{|ccccc|}
\hline Value & $\delta$ & $\sigma$ & MSD & Pearson $(r)$ \\
\hline$T_{\text {re }}(\mathrm{O} C)$ & 0.108 & 0.038 & 0.032 & 0.996 \\
\hline$T_{\text {sk }}(\mathrm{O})$ & 0.149 & 0.198 & 0.067 & 0.986 \\
\hline
\end{tabular}

\subsection{Passive cooling reinforced by use of an ice jacket during recovery}

Figure 4 shown the experimental values (points) obtained by Lopez et al. (2008) and predicted values (lines) for a situation where, only during recovery phase, passive cooling is reinforced using an ice jacket.

Experimental results were obtained for 10 people preforming a protocol with: (i) preliminary thermal stabilization; (ii) muscle warming $\left(t=10 \mathrm{~min}, T_{\text {air }}{ }^{*}=T_{m r t}{ }^{*}=33^{\circ} \mathrm{C}, R H_{\text {air }}{ }^{*}=50 \%\right.$, $v_{\text {air }}{ }^{*}=0.2 \mathrm{~m} / \mathrm{s}, M^{*}=1.2 \mathrm{met}, I_{c l}{ }^{*}=0.263 \mathrm{clo}, i_{v p}{ }^{*}=0.38$ and $\left.\rho^{*}=0.10\right)$; (iii) exercise $(t=68 \mathrm{~min}$, $T_{\text {air }}=T_{m r t}=33.1^{\circ} \mathrm{C}, \quad R H_{\text {air }}=55.1 \%, \quad v_{\text {air }}=0.6 \mathrm{~m} / \mathrm{s}, \quad M=5.6 \mathrm{met}, \quad I_{c l}=0.263 \mathrm{clo}, i_{v p}{ }^{*}=0.38$ and $\left.\rho^{*}=0.10\right)$; and (iv) recovery $\left(t=35 \mathrm{~min}, T_{\text {air }}=T_{m r t}=26.6^{\circ} \mathrm{C}, R H_{\text {air }}=55.1 \%, \quad v_{\text {air }}=0.2 \mathrm{~m} / \mathrm{s}\right.$, $M=1.0$ met, $I_{c l}=0.445$ clo, $i_{v p}{ }^{*}=0.38$ and $\left.\rho^{*}=0.10\right)$. The results presented in Figure 4 for the core ( $\left.T_{\text {core }}\right)$ and mean skin $\left(T_{s k}\right)$ temperatures reveal a reasonable agreement between the measured and the predicted values for both temperatures.

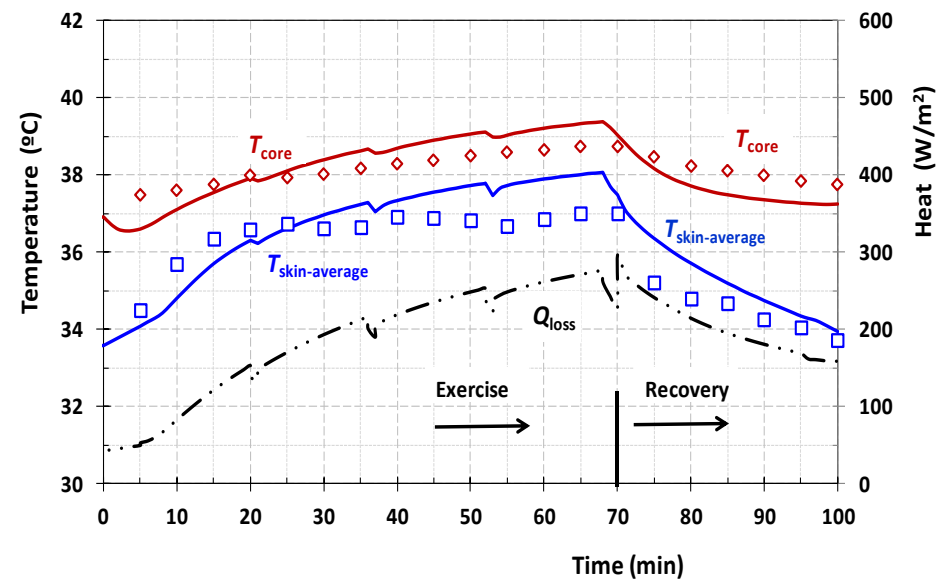

\begin{tabular}{|ccccc|}
\hline Value & $\delta$ & $\sigma$ & MSD & Pearson $(r)$ \\
\hline$T_{\text {core }}(\stackrel{\circ}{ }(\mathrm{C})$ & 0.049 & 0.457 & 0.103 & 0.968 \\
\hline$T_{\text {sk }}(\stackrel{\circ}{ } \mathrm{C})$ & 0.503 & 0.130 & 0.312 & 0.922 \\
\hline
\end{tabular}

Figure 4 - Experimental values (points) obtained by Lopez et al. 2008 and predicted values (lines) for body passive cooling reinforced using an ice jacket during the recovery phase. 


\subsection{Passive cooling reinforced with hands and forearms immersion in cold water during recovery}

The study of Selkirk et al. (2004) aimed to verify the effectiveness of the passive human body cooling technique in reducing thermal stress in a hot thermal environment and where it was necessary to wear personal protective clothing. Fifteen male firefighters participated in the study, for which in average $h=1.81 \mathrm{~m}$ and $w=86.9 \mathrm{~kg}$.

All the steps of the tests were performed in a room with controlled thermal conditions $\left(T_{\text {air }}=T_{m r \mathrm{r}}=35^{\circ} \mathrm{C}, R H_{\text {air }}=50 \%, v_{\text {air }}{ }^{*}=0.1 \mathrm{~m} / \mathrm{s}\right)$. The protocol included the following phases: (i) thermal stabilization in a neutral environment; (ii) muscle warming ( $t^{*}=3 \mathrm{~min}, M^{*}=1.2 \mathrm{met}$ ); (iii) exercise ( $\left.t=20 \mathrm{~min}, M^{*}=2.8 \mathrm{met}\right)$; (iv) transition ( $\left.t=10 \mathrm{~min}, M^{*}=1.5 \mathrm{met}\right)$; (v) exercise $(t=20 \mathrm{~min}$, $M^{*}=2.8 \mathrm{met}$ ); (vi) transition ( $t=5 \mathrm{~min}, M^{*}=1.2 \mathrm{met}$ ); (vii) application of passive recovery reinforced with hands and forearms immersion in water at $T_{\text {water }}=17^{\circ} \mathrm{C}\left(t=20 \mathrm{~min}, M^{*}=0.8 \mathrm{met}\right)$; (viii) transition $\left(t=5 \mathrm{~min}, M^{*}=1.2 \mathrm{met}\right)$; (ix) exercise $\left(t=20 \mathrm{~min}, M^{*}=2.8 \mathrm{met}\right)$. During the exercise phases the subjects wear a typical forest firefighting personal protective ensemble, including individual breathing apparatus $\left(I_{c l}=1.55 \mathrm{clo}, i_{v p}{ }^{*}=0.28\right.$ and $\left.\rho^{*}=0.16\right)$. During the muscle warming and the recovery phases, they remove the helmet, the flash hood, the gloves, the jacket and the individual breathing apparatus $\left(I_{c l}{ }^{*}=1.06 \mathrm{clo}, i_{v p}{ }^{*}=0.56\right.$ and $\left.\rho^{*}=0.10\right)$.

Figure 5 shows that the rectal $\left(T_{r e}\right)$ and average skin $\left(T_{s k}\right)$ temperatures experimental results obtained by Selkirk et al. (2004) are in good agreement with the predicted ones, particularly for the rectal temperature.

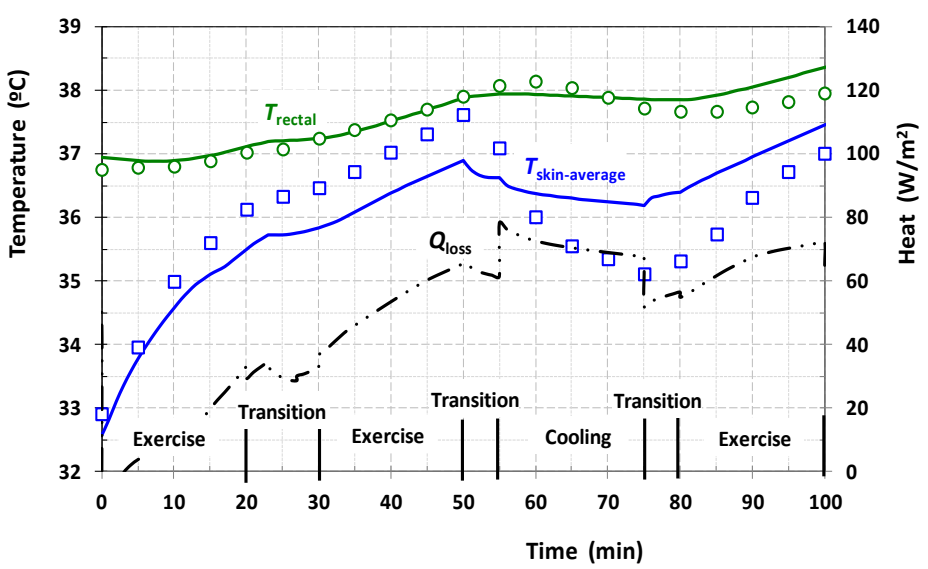

\begin{tabular}{|ccccc|}
\hline Value & $\delta$ & $\sigma$ & MSD & Pearson $(r)$ \\
\hline$T_{\text {re }}(\stackrel{\circ}{ } \mathrm{C})$ & -0.205 & 0.248 & 0.052 & 0.946 \\
\hline$T_{\text {sk }}(\stackrel{\circ}{ } \mathrm{C})$ & -0.500 & 0.862 & 0.162 & 0.731 \\
\hline
\end{tabular}

Figure 5 - Experimental values (points) obtained by Selkirk et al. 2004 and predicted values (lines) for body cooling by immersion of hands and forearms in cold water during the recovery phase.

\subsection{Recovery with passive cooling reinforced by use of an ice jacket and by immersion of hands and forearms in cold water}

Figure 6 shown the experimental values (points) obtained by Barr et al. (2009) and predicted values (lines) for a situation where, only during recovery phase, passive cooling is reinforced by the use of an ice jacket and by the immersion of hands and forearms in water at $T_{\text {water }}=19^{\circ} \mathrm{C}$.

Experimental values were obtained with 9 firefighters wearing firefighting personal protective clothing and performing the following protocol: (i) preliminary thermal stabilization; (ii) muscle warming; (iii) exercise; (iv) recovery; and (v) exercise. The exercise phases are characterized by $t=20 \mathrm{~min}, T_{a i r}=T_{m r t}=50^{\circ} \mathrm{C}, R H_{a i r}=13 \%, v_{a i r}=0.2 \mathrm{~m} / \mathrm{s}, M=5.0 \mathrm{met}, I_{c l}=2.46 \mathrm{clo}, i_{v p}{ }^{*}=0.34$ and 
$\rho^{*}=0.10$. The recovery phase is characterized by $t=15 \mathrm{~min}, T_{\text {air }}=T_{m r t}=21^{\circ} \mathrm{C}, R H_{\text {air }}=60 \%$, $v_{\text {air }}=0.5 \mathrm{~m} / \mathrm{s}, M=0.8 \mathrm{met}, I_{c l}=1.58 \mathrm{clo}, i_{v p}{ }^{*}=0.30, \rho^{*}=0.10$ and $T_{\text {water }}=19^{\circ} \mathrm{C}$.

The results presented in Figure 6 for the core $\left(T_{\text {core }}\right)$ and mean skin $\left(T_{s k}\right)$ temperatures reveal a satisfactory agreement between the measured and the predicted values for both temperatures.
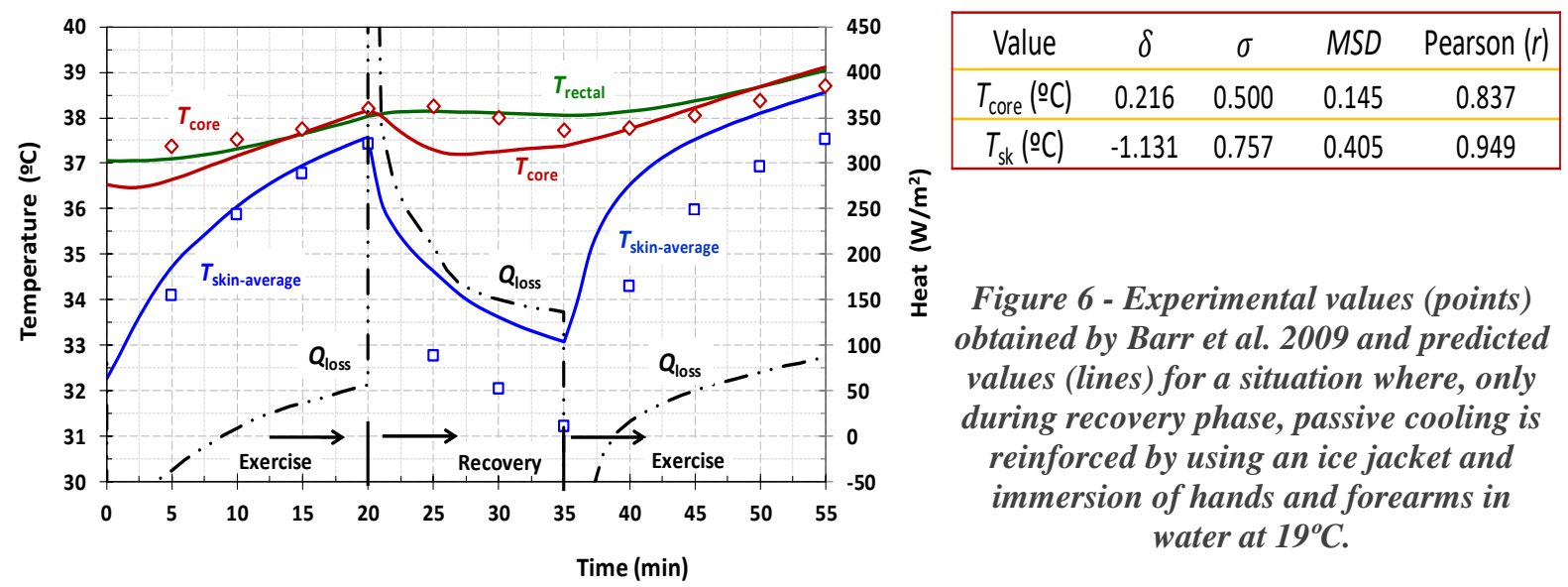

\section{Discussion}

In the present paper, the applicability of the HuTheReg program was tested with several cases, each involving different periods (phases) with distinct levels of metabolic activity, clothing thermal insulations, environmental conditions and body cooling techniques.

This paper presents different human body cooling techniques. The ones that can be used during the exercise phases have the advantage of dissipating the excess of heat as it is being generated. However, the use of ice jackets during exercise periods is not always possible. The application of body cooling techniques during recovery periods is usually easier to accomplish. All of them have shown to be beneficial in terms of reducing hyperthermic stress, and their efficiency can be even enhanced by simultaneous application of more than one technique.

To cover a wide range of situations, the applicability of the program was tested by applying it to several different cases, each involving several periods (phases) with distinct levels of body metabolic activity, clothing characteristics, environment conditions and human body cooling actions. No limitations were found on the program's ability to predict the thermophysiological behavior of the human body when exposed to a wide range of situations, even in cases involving periods with very different conditions.

In all the assessments tested the quality of the program's forecasts can be classified as very acceptable. This statement is based on the statistical comparison between experimental and predicted values. Some predictions were not as good as expected. That shall not be exclusively attributed to the pro-gram but most probably to the number of estimations that were necessary to perform due to the insufficient detail and lack of data found in the scientific papers related to this subject.

The results obtained with this study put in evidence the importance of simulation programs to carry out detailed evaluations of the thermophysiological response of the human body, which allows the anticipation of actions to attenuate thermal stress and thus avoid the advent of heat-related illnesses. 


\section{Conclusions}

A software for the simulation of the human body thermoregulation, the HuTheReg program, was tested against experimental results from the literature, which were obtained using real persons. At the same time, an assessment of the effectiveness of some human body cooling techniques capable to mitigate the risk of heat stress by hyperthermia was done.

Although with very different effectiveness, all body cooling techniques considered proved to be capable to mitigate the level of hyperthermic stress of firefighters engaged in firefighting activities.

No limitations were found on the program's ability to predict the human body thermophysiological behavior. A very acceptable outcome was obtained in all cases, being excellent in several of them.

The results show that it is reasonable to use simulation programs to carry out detailed evaluations of the human body thermophysiological response, allowing the anticipation of actions to attenuate thermal stress and thus avoiding of the advent of heat-related disorders.

\section{References}

Abreu RM, Raimundo AM, Quintela DA (2014). Analysis of the thermophysiological response to cooling techniques in firefighters, ICFFR $2014-7^{\text {th }}$ International Conference on Forest Fire Research, paper H01, Coimbra, Portugal, 14 - 21 november 2014.

Barr D, Gregson W, Sutton L, Reilly T (2009). A practical cooling strategy for reducing the physiological strain associated with firefighting activity in the heat, Ergonomics 52(4): 413-420.

Barr D, Gregson W, Reilly T (2010). The thermal ergonomics of firefighting reviewed, Applied Ergonomics, 41: 161-172.

Carter JB, Banister EW, Morrison JB (1999). Effectiveness of rest pauses and cooling in alleviation of heat stress during simulated fire-fighting activity, Ergonomics 42: 299-313.

Chou C, Tochihara Y, Kim T (2008). Physiological and subjective responses to cooling devices on firefighting protective clothing, European J Applied Physiology 104: 367-374.

Colburn D, Suyama J, Reis S (2011). A comparison of cooling techniques in firefighters after a live burn evolution, Prehospital Emergency Care 15: 226-232.

Fiala D, Lomas KJ, Stohrer M (1999). A computer model of human thermoregulation for a wide range of environmental conditions - the passive system, J Applied Physiology 87: 1957-1972.

Giesbrecht GG, Jamieson C, Cahill F (2007). Cooling hyper-thermic firefighters by immersing forearms and hands in $10^{\circ} \mathrm{C}$ and $20^{\circ} \mathrm{C}$ water, Aviation Space Environmental Medicine 78: 561-567.

Hardy JD, Stolwijk JAJ (1966). Partitional calorimetric studies of responses man during exposures to thermal transients, J Applied Physiology 21: 967-977.

Havenith G, Holmér I, Parsons K (2002). Personal factors in thermal comfort assessment - clothing properties and metabolic heat production, Energy and Buildings 34: 581-591.

Henriques F (1947). Studies of thermal injury V. The predictability and the significance of thermally induced rate processes leading to irreversible epidermal injury, Archives of Pathology 43: 489-502.

Hostler D, Reis S, Bednez JC, Kerin S, Suyama J (2010). Comparison of active cooling devices with passive cooling for rehabilitation of firefighters performing exercise in thermal protective clothing: a report from the Fireground Rehab Evaluation (FIRE) trial, Prehospital Emergency Care 14: 300309.

Huizenga C, Zhang H, Duan T, Arens E (1999). An improved multinode model of human physiology and thermal comfort, Proceedings of IBPSA Building Simulation 99, Kyoto, Vol. 1, pp 353-359. 
Konz S, Hwang C, Dhiman B, Duncan J, Masud A (1977). An experimental validation of mathematical simulation of human thermoregulation, Computers in Biology and Medicine 7: 71-82.

Lopez RM, Cleary MA, Jones LC, Zuri RE (2008). Thermoregulatory Influence of a Cooling Vest on Hyperthermic Athletes. J Athletic Training 43(1): 55-61.

Mündel T, King J, Collacott E, Jones DA (2006). Drink temperature influences fluid intake and endurance capacity in men during exercise in a hot dry environment, Experimental Physiology 91(5): 925-933.

Oliveira AVM, Gaspar AR, Quintela, DA (2008). Measurements of clothing insulation with a thermal manikin operating under the thermal comfort regulation mode: comparative analysis of the calculation methods, European J Applied Physiology 104: 679-688.

Oliveira AVM, Gaspar AR, Quintela DA (2011). Dynamic Clothing insulation. Measurements with a thermal manikin operating under the thermal comfort regulation mode, Applied Ergonomics 42(6): 890-899.

Quintela DA, Gaspar AR, Borges C (2004). Analysis of sensible heat exchanges from a thermal manikin, European J Applied Physiology 92(6): 663-668.

Raimundo AM, Gaspar AR, Quintela DA (2004). Numerical modelling of radiative exchanges between the human body and surrounding surfaces, Climamed $2004-1$ st Mediterranean congress of climatization, 16-17 of April, Lisbon, Portugal, paper 8/1.

Raimundo AM, Figueiredo AR (2009). Personal protective clothing and safety of firefighters near a high intensity fire front, Fire Safety Journal 44: 514-521.

Raimundo AM, Quintela DA, Gaspar AR, Oliveira AVM (2012). Development and validation of a computer program for simulation of the human thermophysiological response, Portuguese chapter of IEEE-EMBS, ISBN:978-1-4673-4524-8.

Selkirk G, McLellan TM \& Wong J (2004). Active versus passive cooling during work in warm environments while wearing firefighting protective clothing, J. Occupational Environment and Hygiene 1: 521-531.

Stolwijk JAJ (1971). A mathematical model of physiological temperature regulation in man. NASA Contractor Report CR-1855, NASA, Washington, DC.

Tanabe S, Kobayashi K, Nakano J, Ozeki Y, Konishi M (2002). Evaluation of thermal comfort using combined multi-node thermoregulation $(65 \mathrm{MN})$ and radiation models and computational fluid dynamics (CFD), Energy and Buildings 34: 637-646.

Werner J, Reents T (1980). A contribution to the topography of temperature regulation in man, European J Applied Physiology 45: 87-94.

Wissler EH (1985). Mathematical simulation of human thermal behaviour using whole body models, In: Shitzer A, Eberhart RC, (Eds), Heat Transfer in Medicine and Biology - Analysis and Applications. Plenum, New York London, pp 325-373.

Wyndham C, Ward J, Strydom N, Morrison J, Williams C, Bredell G, Peter J, Von Rahden M, Holdsworth L, Van Graan C, Van Rensburg A, Munro A (1964). Physiological reactions of caucasian and bantu males in acute exposure to cold, J Applied Physiology 19: 538-592. 